\title{
Promoting healthy lifestyles using information technology during the COVID-19 pandemic
}

\author{
Snehil Dixit ${ }^{1, *}$, Girish Nandakumar ${ }^{2}$ \\ ${ }^{1}$ Department of Medical Rehabilitation Sciences, College of Applied Medical Sciences, King Khalid University, 61321 Abha, Kingdom of Saudi Arabia \\ ${ }^{2}$ Department of Physiotherapy, Manipal College of Health Professions, Manipal Academy of Higher Education, Manipal, 576104 Karnataka, India \\ *Correspondence: snehildixit83@gmail.com (Snehil Dixit)
}

DOI:10.31083/j.rcm.2021.01.187

This is an open access article under the CC BY 4.0 license (https://creativecommons.org/licenses/by/4.0/).

Submitted: 19 September 2020 Revised: 28 December 2020 Accepted: 28 December 2020 Published: 30 March 2021

In this pandemic era there exist a relationship between a sedentary lifestyle during lockdown with periods of anxiety and stress among the population. Moreover, the population with chronic disease will be vulnerable to the ill effects of a physically inactive lifestyle. Besides, social media platforms and technological advances also appear to be another potential tool for promoting health and wellbeing, however, the capability of these interventions during the pandemic era is largely unknown. To explore the possible role of technological advances and social media platforms as an alternate tool in promoting a healthy living style during the COVID-19 era. The studies with the predefined criteria were used to synthesize information regarding the opportunities and challenges. Studies delivering lifestyle intervention using social media platforms, technologies for health promotion were considered for the review. The studies included to synthesize evidence were randomized controlled trials, systematic reviews and meta-analysis. Database like Medline, Scopus, and Science Direct were searched independently by two reviewers. A total of 17 studies were included in the review, Internet and lifestyle modification $n=2$, mHealth and lifestyle modification $n=3$, Social media and lifestyle modifications $n=3$, technology adoption for lifestyle modification $n=4$, and hazards $=5$. Technology and social media-based interventions appear to be a promising technique for promoting health and wellbeing and it is the only effective method for delivering an intervention during a pandemic situation. However, there also appears a need for the development of guidelines for social media usage to prevent probable hazards.

\section{Keywords}

Pandemic; Physical activity; Technology-assisted; Social media; Lifestyle modifications

\section{Introduction}

Rapid human to human transmission of the virus with pneumonia-like symptoms of unknown etiology was confirmed by the World Health Organization (WHO) in China by December 2019. Within no time the virus became a global threat causing worldwide morbidity and mortality. WHO classified the virus as the severe acute respiratory syndrome coronavirus-2 (SARS-CoV-2), causing an illness named coronavirus disease-2019 (COVID-19) [1].

Then started an unprecedented worldwide series of lock- downs to prevent rapid human transmission which was causing a surge in the global cases of the infection. Initially, a lockdown was considered to be an effective strategy in the suppression of the spread of virus infection [2]. The lockdown periods were associated with a sedentary lifestyle, anxiety, and depression among the healthy and diseased population due to uncertainties arising from the pandemic [3]. The after impacts of sedentary lifestyle affected children and adults to some extent and to great extent the elderly population who were already at risk of complications [4].

To add further, studies have also demonstrated negative psychological impacts of social isolation, leading to a greater amount of anxiety, stress, fear, and depressive symptoms $[3,5]$. These symptoms are not only limited to the general population but are also affecting the clinicians with stress and burnout leading to higher rates of drug and alcohol addiction, divorce, and suicide [6]. Such circumstances may also negatively influence the medical delivery system.

Sedentary behaviors of the population amid the lockdown may expose them to the risk of overweight, prediabetes, obesity, diabetes, hypertension, and cardiovascular diseases. Diseases like overweight, diabetes, and obesity alone or in combination are associated with greater chances of developing cardiovascular and cerebrovascular events [7]. Sedentary behaviors or Physical Inactivity alone is recognized as a global health threat in low, middle- and high-income countries [8].

There is a necessity to explore real-time, cost-effective population-based interventions such as primary and secondary prevention schemes for the population. As there are factors which interplay a role in shaping an individual's lifestyle and habits, hence it can also interplay a decisive role in deciding an individual's risk for developing health hazards [9].

Health promotion interventions and lifestyle behavioral changes using the social media platform and technologyassisted gadgets may help to overcome the risks imposed by lockdowns. Social media platforms can play an important role in social support to promote healthy behavioral attitudes and behaviors [7]. Perception for support may carry im- 


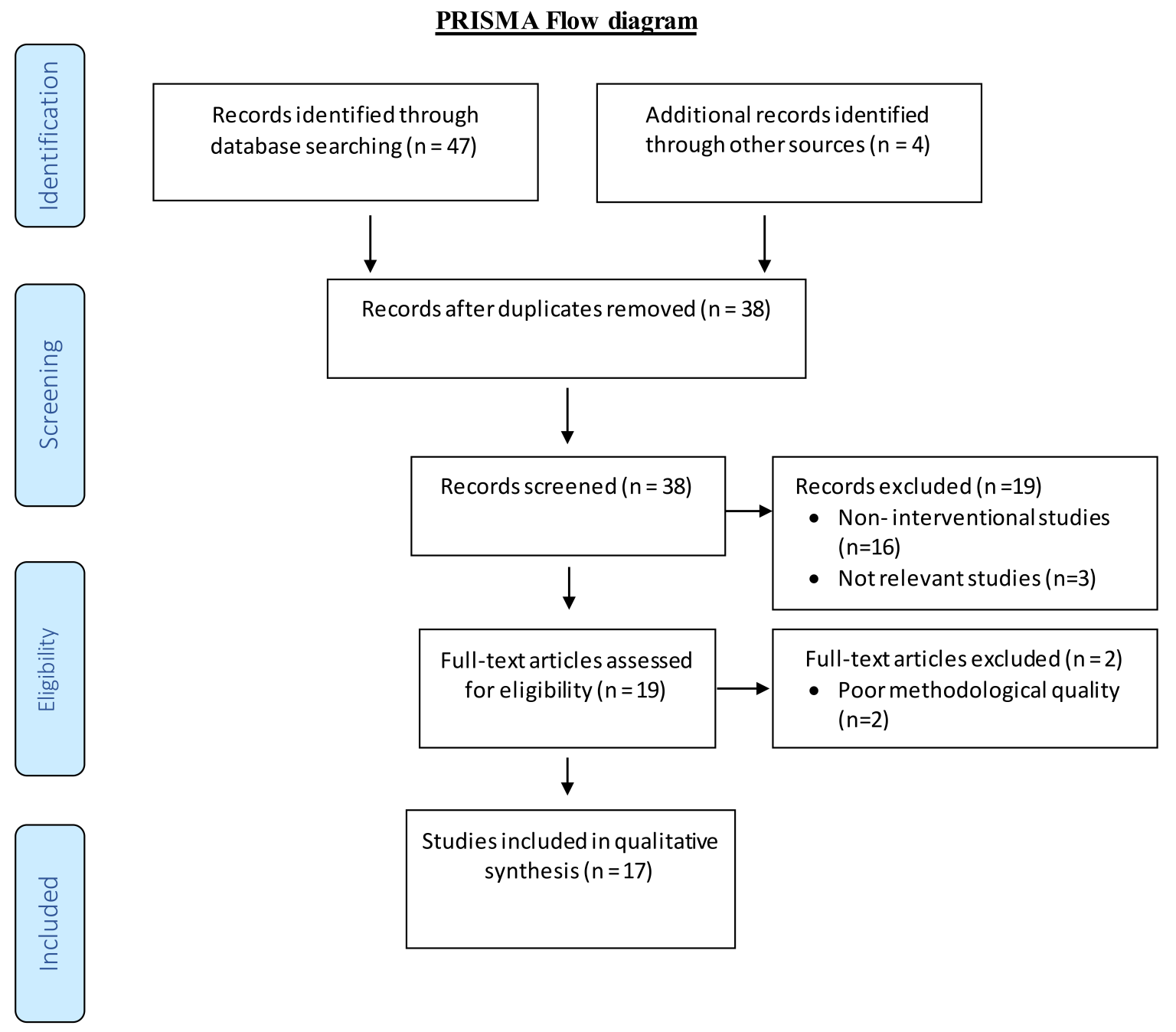

Fig. 1. Depicts the PRISMA flow chart for the identification, screening and inclusion of the studies for the review process.

portant psychological benefits, thereby increasing the level of participation in health-related programs [7]. Moreover, group exercise interaction sessions among like-minded people and their 'shared experiences' may help ineffective administration and higher adherence to the physical activity program by 'social bonding'.

Wearable technologies are an important aspect for not only promoting social interaction but also healthy behaviors through physical activity. Wearable technologies have the potential to motivate individuals through social recommendations, interpersonal interactions, competitions based thinking, and intra-cooperation of the group [10]. The technologies that are worn on the body such as smartwatches, smartphones, wristbands are self-tracking gears proficient in monitoring step counts during walking, running, oxygen consumptions, games intensities, vital signs, weight, fitness, sleep cycle, diet, and emotions [10].

Moreover, through this review, there appears a definite need in the COVID-19 era to precisely outline the necessity to explore the alternative pathway and its effectiveness in promoting or enhancing the health benefits of the population.
Hence the objective of the present review was to explore the possible role of technological advances and social media platforms as an alternate mode in promoting a healthy lifestyle among people at risk and with acute and chronic conditions. Thereby exploring the opportunities, advantages, and challenges associated with it during the COVID-19 era.

\section{Methodology}

Medline, Scopus, and Science direct database were searched using the following keywords lifestyle modifications OR physical activity AND pandemic, OR COVID 19, challenges OR difficulties OR barriers, opportunities OR facilitators using the boolean terms AND or OR. Title and abstract screening were performed by the authors. Selected articles were retrieved in full text and investigated according to the inclusion criteria, by two authors. Disagreements between the two authors were discussed and resolved. The reference list of all the included articles was further screened for the selection of potentially relevant articles. 


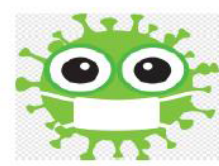

corona virus

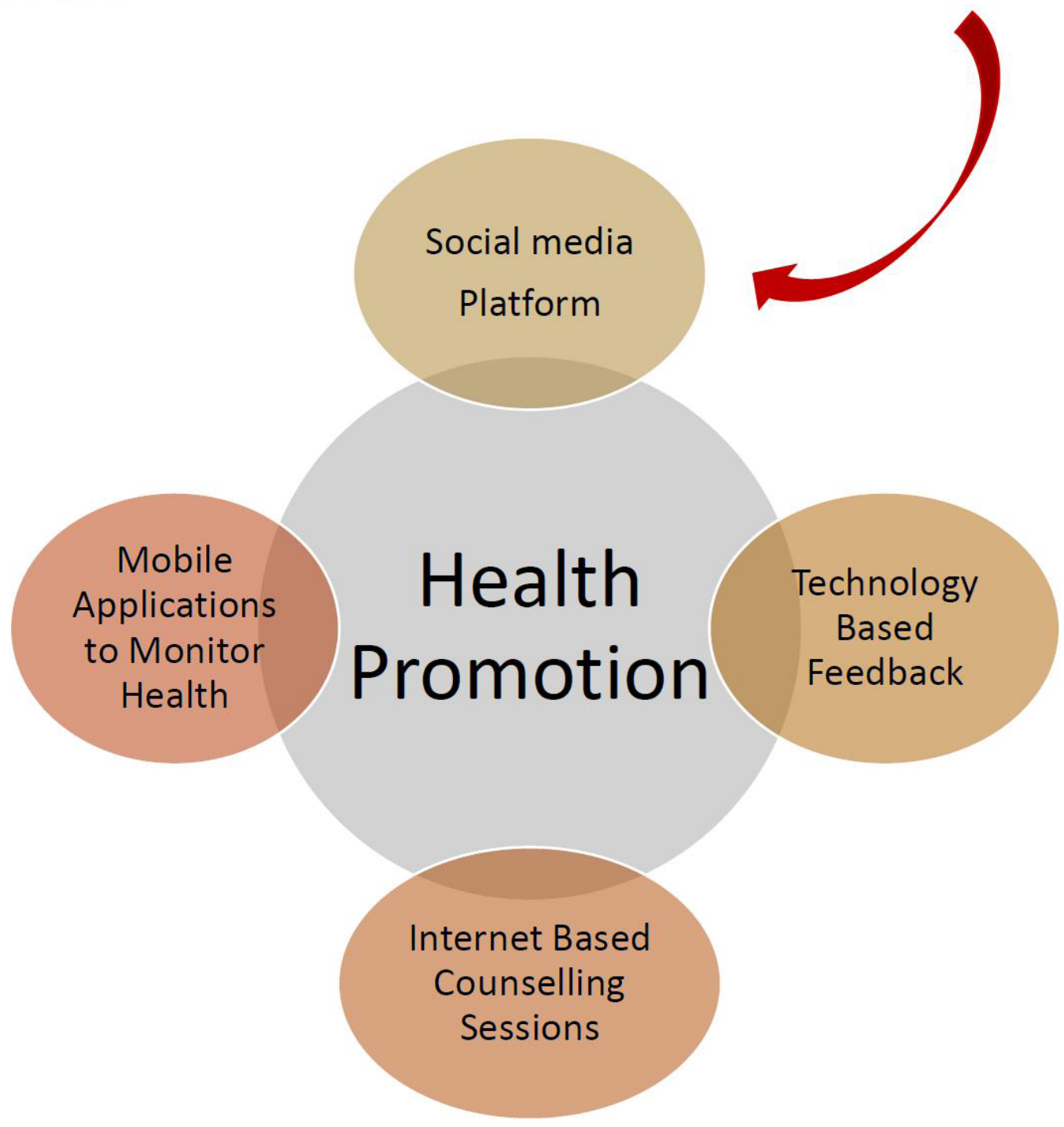

Fig. 2. Represents figure for utilisation of health services for promoting health among elderly, young and people with various Comorbidities.

Data extraction was done by one author using a data extraction form containing the following information. The first author's last name, year of publication, country of study conduct, study design, sample size, sex and age of the patients, type of lifestyle modification and technology used, challenges, and opportunities. The accuracy of the information was checked by the second author. Two authors independently reviewed each abstract of identified articles. Studies were excluded at this stage if both reviewers agreed that the eligibility criteria were clearly not met. If either reviewer could not exclude the study based on the abstract, the full article was reviewed independently by two authors. Studies or reviews were included in this narrative review which highlighted the interventional role of internet/social me$\mathrm{dia} /$ technological advances in health promotion/physical activity in the population. Studies were excluded if they weren't related to the intervention in focus or metanalysis or the focus of the study/review was secondary treatment. Viewpoints and narrative reviews were also considered for the generation of evidence or suggestion for the current review.

\section{Results}

The studies were selected according to the predefined criteria. Only selected studies $\mathrm{n}=17$ were taken into account using the search criteria with the predefined measures using specific keywords. The details of which are discussed in Fig. 
1. The details of which are as following under Internet and lifestyle modification $\mathrm{n}=2$, mHealth and lifestyle modification $n=3$, Social media and lifestyle modifications $n=3$, and technology adoption for lifestyle modification $n=4$ and hazards $=5$. A short description of the studies included for the review is given in Table 1 .

\section{Discussion}

Technological innovations have played an important role in lifestyle modifications and their adherence among healthy as well as among patient populations in recent times. Incorporation of technology in the form of websites, webpages, and wikis; mobile devices and applications; social media and social networking channels; video chat, video sharing, and podcast media; wearable devices and training devices to promote lifestyle interventions have been reported by various researchers. The amalgamation of these services and technologies to encourage the health delivery system for health promotion is depicted in Fig. 2 during the pandemic time.

\subsection{Internet and lifestyle modification}

The internet and related technologies present a widely accessible, round the clock means to promote disease management and facilitate lifestyle modification. The implementation of web-based interventions to assist with lifestyle modification was stated in papers over the last decade. The majority of the web-based programs included physical activity (PA) promotion, dietary intervention, smoking cessation, and psychological interventions. These internet-based programs used specific theory/conceptual framework to design their intervention, which included self-efficacy/social cognitive theory, social support theory, social-ecological framework, health belief model, and transtheoretical model [10]. Studies on web-based PA promotion programs and adherence to lifestyle modification interventions are for obese, overweight population, individuals at risk for cardiovascular diseases (CVD), Diabetes Mellitus, Hypertension, and Chronic Obstructive Pulmonary Diseases.

Cotterez et al. (2014) reviewed studies that used internetbased interventions to promote lifestyle modification among adults with type 2 diabetes in PubMed. The results of the review have demonstrated an improvement in diet and/or physical activity and improvements in glycemic control when web-based strategies are adopted thereby providing a viable option for facilitating diabetes self-management. They have reported that a successful web-based intervention program should be theory-based, with interactive components, personalized feedback, and opportunities for peer support [11].

Franklin et al. 2015 [12] have done a review on information and communication technology (ICT) driven personal health technologies and their role in promoting and supporting self-care behaviors for primary prevention and secondary prevention of cardiovascular diseases (CVD). Successful technological interventions for a positive behavior change using online resources and methods for the delivery of these interventions in CVD prevention has been focused
[12]. It has been substantiated that the online educational resources can be customized or individually tailored to successfully meet the goals of rehabilitation sciences. The degree of self-monitoring and the level of personalized feedback or other interactions are also other factors influencing the efficacy of ICT-driven personal health technologies. The researchers have identified the technological tools and resources like Internet-based communications, mobile devices and applications, social media, and wearable monitors which can be strategically leveraged to enhance self-care behaviors for CVD risk reduction and enhancing secondary prevention [12].

\section{2 mHealth and lifestyle modifications}

Mobile health (mHealth) is a component of electronic health, supported by mobile devices, such as mobile phones, patient monitoring services, or other wireless devices utilized for medical and public health practice. mHealtlh majorly involves the utilization of text messaging, bluetooth and global positioning system (GPS) and voice response calls in mobile devices for primary and secondary prevention of diseases as well as for improving the adherence of individuals in lifestyle modification interventions. Recently there is a developing trend for technologically advanced insoles that can have bluetooth and GPS connectivity to mobiles or smartwatches. It can help to identify individuals with frequent musculoskeletal problems at the risk of fall-related injuries and at the same time can encourage a variety of activities in all the age groups by giving valid step counts, calories spent, and so on [13].

The evidence on mobile health (mHealth) tools, including interactive voice response (IVR) calls, short message service (SMS) or text messaging, and smartphones, in improving lifestyle behaviors and management related to cardiovascular diseases throughout the world was reviewed by Piette et al. 2015 [13]. It was reported that addressing risk factors including weight management, smoking cessation, and physical activity improvement as cardiovascular preventive care could be performed by IVR and SMS-based interventions. There is evidence that shows benefits concerning hypertension management, reduction in hospital readmissions, and diabetic glycemic control. Multi-channeled treatment prospects including web-based communication with clinicians and mHealth-enabled clinical monitoring with feedback also have shown benefits. Emerging evidence suggests that mHealth interventions may improve cardiovascular-related lifestyle thereby reducing the events associated with it [13].

Hamilton et al. (2018) [14] have reviewed and assessed the evidence of mHealth interventions for cardiac rehabilitation and management of heart failure using an evidence-based approach. The authors have identified 586 papers and after screening and eligibility checking, 9 articles were included for the final synthesis of evidence. The results showed that mHealth was comparable with the traditional center-based cardiac rehabilitation and it was feasible with high rates of patient engagement, acceptance, and adherence [14]. 


\begin{tabular}{lllll} 
Title & Authors & Journal & Objective & Finding \\
\hline
\end{tabular}

Internet interventions to support Cotterez AP, Durant N, J Diabetes Complica- To identify studies that used Internet- Web-based strategies provide a vi- This review suggests the usage of weblifestyle modification for diabetes Agne AA, Cherrington tions [Internet]. 2014 based interventions to promote lifestyle able option for facilitating diabetes based interventions for lifestyle modifica-

management: A systematic review of $\quad$ AL $\quad$ Mar; 28 (2): 243-51. modification among adults with type 2 di- self-management. the evidence. modificetic.

Personal health technology: A new Franklin NC, Lavie CJ, Postgrad Med [Inter- To provide an overview of information We conclude that all the technologi- Soft technology could be utilized to deliver era in cardiovascular disease preven- $\quad$ Arena RA. net]. 2015 Mar 4; 127 and communication technology-driven cal tools and resources identified can be primary and secondary prevention stratetion. (2): 150-8. net]. $2015 \mathrm{Mar} 4 ; 127$ and communication technology-driven cal tools and resources identified can be primary and secondary preven
(2): 150-8. potential role in promoting and support- behaviors for CVD risk reduction and sec-

ing self-care behaviors for primary and ondary prevention.

secondary prevention of cardiovascular

diseases.

Mobile Health Devices as Tools for Piette JD, List J, Rana Circulation [Internet]. To examine evidence on mobile health mHealth intervention programs are feasi- Mobile health tools may be a feasible opduction and Disease Management. Striplin D, Heisler M. 2012-27. Voice Response (IVR) calls, short mes- ence and disease outcomes. Emerging tions and in improving adherence to medsage service (SMS) or text messaging, evidence suggests that mHealth interven- ication and exercises. and smartphones, in improving lifestyle tions may improve cardiovascular-related behaviors and management related to lifestyle.

cardiovascular diseases throughout the world

Smartphones in the secondary pre- Hamilton SJ, Mills B, BMC Cardiovasc Dis- To assess the evidence around mHealth in- The review found that mHealth delivery This review highlights the importance of vention of cardiovascular disease: a Birch EM, Thompson ord [Internet]. 2018 terventions for cardiac rehabilitation and for cardiac rehabilitation and heart failure mHealth tools in the delivery of secondary systematic review. $\quad$ SC. Dec 7; 18 (1): $25 . \quad$ heart failure management. management was feasible with high rates prevention strategies among individuals of participant engagement, acceptance, us- with cardiovascular disease. age and adherence.

Effects of a weight management Jane M, Hagger M, Atkin SL, editor. PLoS To evaluate the effectiveness of using so- The group which received a weight reduc- Social media platforms could be effectively program delivered by social media Foster J, Ho S, Kane R, One [Internet]. 2017 cial media to augment the delivery of and tion program through social media (Face- used to deliver weight management proon weight and metabolic syndrome Pal S. Jun 2; 12 (6): e0178326. provide support for a weight management book) reported a 4.8\% reduction in weight. gram. risk factors in overweight and obese Jun 2; 12 (6): e0178326.
provide s
program

adults: A randomized controlled 
Table 1. Continued

\begin{tabular}{|c|c|c|c|c|c|}
\hline Title & Authors & Journal & Objective & Finding & Implications for practice \\
\hline $\begin{array}{l}\text { Findings of the Chronic Obstruc- } \\
\text { tive Pulmonary Disease-Sitting and } \\
\text { Exacerbations Trial (COPD-SEAT) } \\
\text { in Reducing Sedentary Time Using } \\
\text { Wearable and Mobile Technologies } \\
\text { With Educational Support: Ran- } \\
\text { domized Controlled Feasibility Trial. }\end{array}$ & $\begin{array}{l}\text { Orme MW, Weedon } \\
\text { AE, Saukko PM, } \\
\text { Esliger DW, Morgan } \\
\text { MD, Steiner MC, et al. }\end{array}$ & $\begin{array}{l}\text { JMIR mHealth uHealth } \\
\text { [Internet]. } 2018 \text { Apr } \\
\text { 11;6 (4): e84. }\end{array}$ & $\begin{array}{l}\text { To determine the feasibility and the } \\
\text { acceptability of an education and self- } \\
\text { monitoring intervention using wearable } \\
\text { technology to reduce sedentary behavior } \\
\text { for individuals with chronic obstructive } \\
\text { pulmonary disease admitted to hospital for } \\
\text { an acute exacerbation. }\end{array}$ & $\begin{array}{l}\text { A significant reduction in sedentary time } \\
\text { has been noticed among those who had } \\
\text { used a wearable device. }\end{array}$ & $\begin{array}{l}\text { The utilization of wrist-worn wearable } \\
\text { devices to reduce sedentary time has been } \\
\text { highlighted. }\end{array}$ \\
\hline $\begin{array}{l}\text { A narrative synthesis systematic re- } \\
\text { view of digital self-monitoring inter- } \\
\text { ventions for middle-aged and older } \\
\text { adults. }\end{array}$ & $\begin{array}{c}\text { Bartels SL, van } \\
\text { Knippenberg RJM, } \\
\text { Dassen FCM, Asaba E, } \\
\text { Patomella A-H, } \\
\text { Malinowsky C, et al. }\end{array}$ & $\begin{array}{l}\text { Internet Interv [Inter- } \\
\text { net]. } 2019 \text { Dec; 18: } \\
100283\end{array}$ & $\begin{array}{l}\text { To provide a comprehensive overview of } \\
\text { technology-based self-monitoring inter- } \\
\text { vention that intends to improve health in } \\
\text { middle-aged and older adults. }\end{array}$ & $\begin{array}{l}\text { The authors have found that digital self- } \\
\text { monitoring technology with automated } \\
\text { and personalized feedback is needed for } \\
\text { health improvements. }\end{array}$ & $\begin{array}{l}\text { Digital self-monitoring technology could } \\
\text { be used to monitor the health improve- } \\
\text { ments. }\end{array}$ \\
\hline $\begin{array}{l}\text { Effectiveness of eHealth interven- } \\
\text { tions for the promotion of physical } \\
\text { activity in older adults: A systematic } \\
\text { review. }\end{array}$ & $\begin{array}{l}\text { Muellmann S, } \\
\text { Forberger S, Möllers T, } \\
\text { Bröring E, Zeeb H, } \\
\text { Pischke CR. }\end{array}$ & $\begin{array}{l}\text { Prev Med (Baltim) [In- } \\
\text { ternet]. } 2018 \text { Mar; 108: } \\
\text { 93-110. }\end{array}$ & $\begin{array}{l}\text { To compare the effectiveness of eHealth } \\
\text { interventions promoting physical activ- } \\
\text { ity with either no intervention or a non- } \\
\text { eHealth intervention. }\end{array}$ & $\begin{array}{l}\text { The review has concluded that partici- } \\
\text { pation in eHealth intervention led to an } \\
\text { increase in physical activity when com- } \\
\text { pared to no intervention, however, there } \\
\text { is no conclusive evidence to determine } \\
\text { that eHealth interventions are better over } \\
\text { non-eHealth intervention. }\end{array}$ & $\begin{array}{l}\text { eHealth interventions appear to be } \\
\text { promising in physical activity promotion } \\
\text { among older adults. }\end{array}$ \\
\hline $\begin{array}{l}\text { Effects of Mobile Health App In- } \\
\text { terventions on Sedentary Time, } \\
\text { Physical Activity, and Fitness in } \\
\text { Older Adults: Systematic Review } \\
\text { and Meta-Analysis. }\end{array}$ & $\begin{array}{l}\text { Yerrakalva D, } \\
\text { Yerrakalva D, Hajna S, } \\
\text { Griffin S. }\end{array}$ & $\begin{array}{l}\text { J Med Internet Res [In- } \\
\text { ternet]. } 2019 \text { Nov 28; } \\
21 \text { (11): e14343. }\end{array}$ & $\begin{array}{l}\text { To determine the effect of mHealth app in- } \\
\text { terventions on sedentary time, physical ac- } \\
\text { tivity, and fitness in older adults. }\end{array}$ & $\begin{array}{l}\text { The review reported that mHealth App } \\
\text { interventions may be associated with re- } \\
\text { duced sedentary time, increase in physical } \\
\text { activity, and improved fitness. }\end{array}$ & $\begin{array}{l}\text { Fitness and physical activity among older } \\
\text { adults could be improved using mHealth } \\
\text { App interventions. }\end{array}$ \\
\hline $\begin{array}{l}\text { e-Health interventions for healthy } \\
\text { aging: a systematic review. }\end{array}$ & $\begin{array}{l}\text { Buyl R, Beogo I, } \\
\text { Fobelets M, Deletroz } \\
\text { C, Van Landuyt P, } \\
\text { Dequanter S, et al. }\end{array}$ & $\begin{array}{l}\text { Syst Rev [Internet]. } \\
2020 \text { Dec 3; } 9 \text { (1): } 128 .\end{array}$ & $\begin{array}{l}\text { To summarize evidence on the effective- } \\
\text { ness of eHealth interventions on healthy } \\
\text { aging. }\end{array}$ & $\begin{array}{l}\text { eHealth interventions could improve } \\
\text { physical activity. Positive effects were } \\
\text { found on healthy behavior and psycholog- } \\
\text { ical wellness. }\end{array}$ & $\begin{array}{l}\text { Improvement in physical activity among } \\
\text { older adults could be done using e-Health } \\
\text { interventions. }\end{array}$ \\
\hline
\end{tabular}




\section{Table 1. Continued}

\begin{tabular}{|c|c|c|c|c|c|}
\hline Title & Authors & Journal & Objective & Finding & Implications for practice \\
\hline $\begin{array}{l}\text { The combined use of smartphone } \\
\text { and smart band technology in the } \\
\text { improvement of lifestyles in the adult } \\
\text { population over } 65 \text { years: study pro- } \\
\text { tocol for a randomized clinical trial } \\
\text { (EVIDENT-Age study). }\end{array}$ & $\begin{array}{l}\text { Recio-Rodríguez JI, } \\
\text { Lugones-Sanchez C, } \\
\text { Agudo-Conde C, } \\
\text { González-Sánchez J, } \\
\text { Tamayo-Morales O, } \\
\text { Gonzalez-Sanchez S, et } \\
\text { al. }\end{array}$ & $\begin{array}{l}\text { BMC Geriatr [Inter- } \\
\text { net]. } 2019 \text { Dec 23; } \\
\text { 19(1): } 19 .\end{array}$ & $\begin{array}{l}\text { to evaluate the effectiveness of combining } \\
\text { the use of smartphones and smart band } \\
\text { technology for } 3 \text { months with brief coun- } \\
\text { seling on life habits, as opposed to provid- } \\
\text { ing counseling only, in increasing physical } \\
\text { activity and improving adherence to the } \\
\text { Mediterranean diet. }\end{array}$ & On-going & \\
\hline $\begin{array}{l}\text { Lifestyle intervention using the In- } \\
\text { ternet of Things (IoT) for the elderly: } \\
\text { A study protocol for a randomized } \\
\text { control trial (the BEST-LIFE study). }\end{array}$ & $\begin{array}{c}\text { Kato S, Ando M, } \\
\text { Kondo T, Yoshida Y, } \\
\text { Honda H, Maruyama S. }\end{array}$ & $\begin{array}{l}\text { Nagoya J Med Sci [In- } \\
\text { ternet]. } \quad 2018 \text { May; } \\
80(2): 175-82 \text {. }\end{array}$ & $\begin{array}{l}\text { to determine lifestyle interventions using } \\
\text { wearable devices that resulted in lowering } \\
\text { hemoglobin A1c (HbA1c) in Japanese pre- } \\
\text { and early diabetic elderly subjects. }\end{array}$ & On-going & \\
\hline $\begin{array}{l}\text { ACTonHEALTH study protocol: } \\
\text { promoting psychological flexibility } \\
\text { with activity tracker and mHealth } \\
\text { tools to foster healthful lifestyle for } \\
\text { obesity and other chronic health } \\
\text { conditions. }\end{array}$ & $\begin{array}{c}\text { Cattivelli R, } \\
\text { Castelnuovo G, } \\
\text { Musetti A, Varallo G, } \\
\text { Spatola CAM, Riboni } \\
\text { FV, et al. }\end{array}$ & $\begin{array}{l}\text { Trials [Internet]. } 2018 \\
\text { Dec 29; 19(1): } 659 .\end{array}$ & $\begin{array}{l}\text { to compare the effect of the current stan- } \\
\text { dard in obesity treatment to Acceptance } \\
\text { and Commitment Therapy (ACT) and } \\
\text { wearable technology at different times, be- } \\
\text { fore starting the intervention, at the end, } \\
\text { and at follow-up visits of } 3,6 \text {, and } 12 \\
\text { months measuring changes over time of } \\
\text { physical activity and psychological well- } \\
\text { being. }\end{array}$ & On-going & \\
\hline
\end{tabular}


Maddison et al. (2019), outlined the pros and cons of mHealth programs in physical activity interventions and have reported the findings of RCTs that have utilized mHealth interventions in people with CVDs. Mostly the trials have used text messaging programs and wearable sensor technology with mobile and web technology for enhancing physical activity, diet, and interventions for risk factors of CVD. All four trials have shown promising results in terms of improvement in physical activity, adherence to lifestyle behavior, and reduced risk factor markers [15].

There are also studies that state that lockdown, selfisolation periods are associated with increased unhealthy diet behaviors and reduced physical activity $[16,17]$. Especially Quarantine periods are associated stress and anxiety for healthy and people at risk of cardiometabolic diseases [18]. It is also recommended that there is a need for global action supporting physical activity to encourage people to adhere and adapt to healthy lifestyle and habits [18]. Hence internetdriven technologies have a vital role to support a healthy lifestyle, the mobile applications can play a significant role in promoting a healthy lifestyle [18].

\subsection{Social media, wearable devices, and lifestyle modifications}

Jane et al. (2017) evaluated the effectiveness of using social media to augment the delivery of and provide support for, a weight management program delivered to overweight and obese individuals during a twenty-four-week intervention program. The authors revealed that a weight management program with two groups, the first group was given intervention with a Facebook group alongside a support network, while the other group received the same program in a booklet. The results demonstrated a significant reduction in weight, BMI, waist circumference, fat mass, and an improved lean mass and energy intake in the intervention group. This research is a potential example of how social media can be utilized to assist health professionals in weight management of overweight and obese individuals concerning dietary and physical activity modifications [19].

In another study Orme et al. (2018) did a randomized controlled trial on chronic obstructive pulmonary disease patients examining the effect of an education and selfmonitoring intervention using wearable technology (accelerometer) to reduce sedentary behavior. They have used a waist-worn inclinometer linked to a web-based application that provided vibration prompts to encourage movement at defined intervals during the post-hospitalization period. The intervention was readily accepted by most of the patients and health care professionals and it reduced the sedentary behavior of COPD patients [20]. Jane et al. (2018) have critically outlined the efficacy of health promotion interventions delivered through social media in the area of weight management [7]. The authors discussed the importance of social support, social media, health promotion, weight management, and online interactivity. They have further suggested the use of social media for health promotion as it increases participant engagement and is a cost-effective tool in weight man- agement programs [7]

\subsection{Technology adoption for lifestyle modifications among older} adults

Kampmeijer et al. (2016) and Muellmann et al. (2018) briefly highlighted the scope of eHealth and mHealth tools in health promotion and primary prevention among older adults. The authors have also identified apps, websites, devices, video consultations, and webinars as the eHealth and mHealth tools used for health promotion programs in older adults. They have mentioned that the usage of these tools largely depends on the motivation and the support that the older adults receive $[21,22]$. It was found that all the eHealth interventions had tailored physical activity advice with goal setting, feedback, and physical activity tracking. The eHealth interventions were found to be effective in improving the physical activity levels, however, there was no conclusive evidence of its effectiveness over non-eHealth interventions [22].

Bartels et al. (2019) synthesized evidence related to technology-based self-monitoring interventions intended to improve health in middle-aged and older adults. The authors documented that self-monitoring technologies used were interactive voice response, personal digital assistant, short messaging services, smartphone apps, and websites. They have concluded that digital self-monitoring technology with automated and personalized feedback is needed for health improvements among older adults [23].

A systematic review and meta-analysis published in 2019 by Yerrakalva et al. also emphasized the effect of mHealth app interventions on sedentary time, physical activity, and fitness in older adults. It was reported that the mHealth app with data syncing to a wearable device is associated with reduced sedentary time, increased physical activity, and improved fitness [24].

In another systematic review by Buyl et al. (2020) the authors summarized the evidence on the effectiveness of eHealth interventions on healthy aging. The focus areas of the research were medication optimization, remote patient monitoring, assistive technologies, remote training and supervision, disease management, cognitive fitness, and social networking. The review abridged the importance of eHealth interventions that could improve physical activity and could influence health behavior and psychological outcomes [25].

\subsection{Ongoing researches}

In the current scenario, the medical interventions depend a lot on futuristic technologies, some ongoing studies are currently exploring the major role these technological advances may play in day to day life to prevent diseases like type 2 diabetes, hypertension, and cardiovascular diseases. In a study, Recio-Rodriguez and colleagues; 2019 evaluated the effectiveness of combining the use of smartphones and smart band technology for 3 months with counseling on lifestyle habits, as opposed to only counseling. The primary objective of the study was to determine a change in physical activity and ad- 
herence to the Mediterranean diet, and the secondary objectives, to assess the effect of the intervention on body composition, quality of life, independence in activities of daily living, and cognitive performance [26].

The BEST-LIFE trial is another ongoing study on elderly type 2 diabetes mellitus patients by Kato et al. (2017) utilizing wearable monitoring devices loaded with the Internet of things (IoT) that aids them with self-management and health guidance. The outcomes in this study are changes in HbA1c levels and changes in behavioral modification stages. This study is also investigating whether information communication technology tools and monitoring devices loaded with IoT can support health care in elderly subjects [27].

Cattivelli et al. (2018) have initiated a trial among obese individuals to promote adequate healthy behaviors in the natural environment, integrating systematic measurements, continuous feedback, and individualized values-based objectives, by combining Acceptance and Commitment Therapy and wearable technology using Fitbit activity monitor [28].

\subsection{Challenges posed by the technologies during the pandemic}

Though there are various aforementioned opportunities that technology-based activity offers for both healthy and diseased populations through social media and internet-based platforms there are also challenges and hazards that continuous online and technology gadgets pose for an individual. Technologies can be mean to ensure the facility for elementary health services and lifestyle promotion. On the contrary, it is also important to understand the hazards modeled by these technologies on a person and the need for advice or guidelines to selectively use such technological advances during the COVID era. It is vital to understand that these technologies are only an alternate means to help reduce healthrelated inequalities, lower the risk of spreading the virus, and ease access to public services during the crisis [29].

Challenges also include the extent of effective employability of online services in health promotion. Moreover, the determination of the quality of online health services needs to be evaluated. Moreover, poor internet infrastructure will also further impact the delivery of On-online services to the health and population with comorbidities.

\subsubsection{Hazards \\ 4.6.1.1 Impact of increased screen time on the human mind. During} the times of COVID-19, the time spent on screens like that of mobile, computer and television has increased drastically due to the restricted lifestyle. In a study by Madhav et al., it was found that duration of screen time ( $>6$ hours/ day) was associated with moderate or severe levels of depression among the population with age varying from 20-65 years [30]. Authors also suggested that workplace sitting, family history of depression, and the social relationship may also play a vital role in influencing the level of depression.

Another research by World Health Organization (WHO) predicted that by the year 2020 mental health issues including depression will significantly increase the mortality and mor- bidity among adolescents around the world [31]. A major reason behind this can be increased screen time hours spent by children of all age groups. We can understand the seriousness of the problem during the COVID-19 times where the education system throughout the world has become online further increasing the hazards of screen time among the population of all groups. Moreover, there are some reported incidents of suicides due to anxiety, fear, and increased exposure to social media platforms worldwide in the wake of COVID-19 [31, 32]. Such incidents are alarming, reflecting the effect of social media platform hazards in the normal population.

Hence, the organizations need to issue guidelines for the various age group on how to manage increased exposure to screen time to counter the ill effects of electronic-based gadgets and devices which are used today in an uncontrolled manner for educational and other professional purposes.

4.6.1.2 Online education versus traditional education and quality output. Due to unprecedented lockdowns there started an era of the distant mode of working and learning throughout the world. Though this was an effective strategy in the containment of the infection and further spread of COVID-19, it had its pros and cons in the medical education system. The online mode of education offers a set of benefits it broadens the access to quality educational resources, the resources can be accessed anytime by students, better learning outcome achievement, personalized learning experience, and reducing the need for any college-based facilities to be used [31].

Though the online model of education has been often acclaimed to be better than offline or traditional modes of education still there is no evidence that the online mode is superior to the traditional mode [29]. Moreover, online learning can lack instant feedback for both students and teachers thereby compromising satisfaction rate and performance [33]. Authors have also stated that the traditional mode of teaching has more lively sessions, face to face interactions, with instant feedback for both teacher and students with innovative questions and answer sessions [33]. Some researchers have also stated that the traditional way of teaching also allows students to have social interactions and enhance group-based learning which is often more productive than web-based or technology-based learning [33].

In the current scenario, a major threat that looms with the online mode of teaching is sedentary behaviors and lack of social interactions with more time in isolation. However, these challenges can be encountered with proper implementation of physical activity guidelines and simultaneous reduction of screen time among the healthy and diseased population.

\section{Conclusions}

From the current review, it is evident that technology and social media-based interventions can be an effective tool in promoting health and wellbeing among the sedentary population during the pandemic. Technology-based devices and 
social media platforms can play a pivotal role in lifestyle interventions during the COVID 19 era to dispense primary and secondary prevention among the population. Moreover, at present these technological and internet modes are not only safe but also an effective strategy to deliver health care interventions by concurrently maintaining social distance and isolation during the pandemic.

It is also important to understand that the technologybased intervention should be individually tailored with a certain degree of self-monitoring, personalized feedback to meet the need of the afflicted population. However, the undesirable aspect of technology-based intervention programs can also not be ignored and it is of vital importance to recommend or form the guidelines for its usage as an intervention to prevent potential hazards or addiction associated with it.

\section{Author contributions}

SD: Conceptualization, Methodology, Title and abstract screening, Writing- original draft preparation, Visualization, Supervision, Journal submission. GN: Methodology, Database searching, Title and abstract screening, Data extraction, Writing- Review and editing.

\section{Acknowledgment}

The authors declare no funding, no contribution from other persons.

\section{Funding}

The authors did not receive funding for this review.

\section{Conflict of interest}

The authors declare no conflicts of interest statement.

\section{References}

[1] Helmy YA, Fawzy M, Elaswad A, Sobieh A, Kenney SP, Shehata AA. The COVID-19 pandemic: a comprehensive review of taxonomy, genetics, epidemiology, diagnosis, treatment, and control. Journal of Clinical Medicine. 2020; 9: 1225.

[2] Atalan A. Is the lockdown important to prevent the COVID-9 pandemic? Effects on psychology, environment and economyperspective. Annals of Medicine and Surgery. 2020; 56: 38-42.

[3] Antunes R, Frontini R, Amaro N, Salvador R, Matos R, Morouço $\mathrm{P}$, et al. Exploring lifestyle habits, physical activity, anxiety, and basic psychological needs in a sample of portuguese adults during COVID-19. International Journal of Environmental Research and Public Health. 2020; 17: 1-13.

[4] Goethals L, Barth N, Guyot J, Hupin D, Celarier T, Bongue B. Impact of home quarantine on physical activity among older adults living at home during the COVID-19 pandemic: qualitative interview study. Journal of Medical Internet Research. 2020; 22: 1-5.

[5] Brooks SK, Webster RK, Smith LE, Woodland L, Wessely S, Greenberg N, et al. The psychological impact of quarantine and how to reduce it: rapid review of the evidence. The Lancet. 2020; 395: 912-920.

[6] Bansal P, Bingemann TA, Greenhawt M, Mosnaim G, Nanda A, Oppenheimer J, et al. Clinician wellness during the COVID-19 pandemic: extraordinary times and unusual challenges for the allergist/immunologist. The Journal of Allergy and Clinical Immunology: in Practice. 2020; 8: 1781-1790.e3.
[7] Jane M, Hagger M, Foster J, Ho S, Pal S. Social media for health promotion and weight management: a critical debate. BMC Public Health. 2018; 18: 932.

[8] Reis RS, Salvo D, Ogilvie D, Lambert EV, Goenka S, Brownson RC. Scaling up physical activity interventions across the globe: stepping up to larger and smarter approaches to get people moving Physical Activity Series 2 Executive Committee. Lancet. 2016; 388: $1337-1348$.

[9] NHMRC. Clinical practice guidelines for the management of overweight and obesity in adults, adolescents and children in Australia. National Health and Medical Research Council. 2013.

[10] Girginov V, Moore P, Olsen N, Godfrey T, Cooke F, Lu Z. Wearable technology-stimulated social interaction for promoting physical activity: a systematic review. Cogent Social Sciences. 2020; 6: 1742517.

[11] Cotterez AP, Durant N, Agne AA, Cherrington AL. Internet interventions to support lifestyle modification for diabetes management: a systematic review of the evidence. Journal of Diabetes and its Complications. 2014; 28: 243-251.

[12] Franklin NC, Lavie CJ, Arena RA. Personal health technology: a new era in cardiovascular disease prevention. Postgraduate Medicine. 2015; 127: 150-158.

[13] Piette JD, List J, Rana GK, Townsend W, Striplin D, Heisler M. Mobile health devices as tools for worldwide cardiovascular risk reduction and disease management. Circulation. 2015; 132: 20122027.

[14] Hamilton SJ, Mills B, Birch EM, Thompson SC. Smartphones in the secondary prevention of cardiovascular disease: a systematic review. BMC Cardiovascular Disorders. 2018; 18: 25.

[15] Maddison R, Rawstorn JC, Shariful Islam SM, Ball K, Tighe S, Gant N, et al. mHealth interventions for exercise and risk factor modification in cardiovascular disease. Exercise and Sport Sciences Reviews. 2019; 47: 86-90.

[16] Mattioli AV, Ballerini Puviani M, Nasi M, Farinetti A. COVID-19 pandemic: the effects of quarantine on cardiovascular risk. European Journal of Clinical Nutrition. 2020; 74: 852-855.

[17] Mattioli AV, Sciomer S, Cocchi C, Maffei S, Gallina S. Quarantine during COVID-19 outbreak: changes in diet and physical activity increase the risk of cardiovascular disease. Nutrition, Metabolism and Cardiovascular Diseases. 2020; 30: 1409-1417.

[18] Mattioli AV, Sciomer S, Cocchi C, Maffei S. Since January 2020 Elsevier has created a COVID-19 resource centre with free information in English and Mandarin on the novel coronavirus COVID19. The COVID-19 resource centre is hosted on Elsevier Connect, the company's public news and information. 2020. Available at: https://doi.org/10/1016/j/numecd.2020.05.020.

[19] Jane M, Hagger M, Foster J, Ho S, Kane R, Pal S. Effects of a weight management program delivered by social media on weight and metabolic syndrome risk factors in overweight and obese adults: a randomized controlled trial. PLoS ONE. 2017; 12: e0178326.

[20] Orme MW, Weedon AE, Saukko PM, Esliger DW, Morgan MD, Steiner MC, et al. Findings of the Chronic Obstructive Pulmonary Disease-Sitting and Exacerbations Trial (COPD-SEAT) in reducing sedentary time using wearable and mobile technologies with educational support: randomized controlled feasibility trial. JMIR MHealth and UHealth. 2018; 6: e84.

[21] Kampmeijer R, Pavlova M, Tambor M, Golinowska S, Groot W. The use of e-health and $\mathrm{m}$-health tools in health promotion and primary prevention among older adults: a systematic literature review. BMC Health Services Research. 2016; 16: 290.

[22] Muellmann S, Forberger S, Möllers T, Bröring E, Zeeb H, Pischke CR. Effectiveness of eHealth interventions for the promotion of physical activity in older adults: a systematic review. Preventive Medicine. 2018; 108: 93-110.

[23] Bartels SL, van Knippenberg RJM, Dassen FCM, Asaba E, Patomella A, Malinowsky C, et al. A narrative synthesis systematic review of digital self-monitoring interventions for middle-aged and older adults. Internet Interventions. 2019; 18: 100283. 
[24] Yerrakalva D, Yerrakalva D, Hajna S, Griffin S. Effects of mobile health app interventions on sedentary time, physical activity, and fitness in older adults: systematic review and meta-analysis. Journal of Medical Internet Research. 2019; 21: e14343.

[25] Buyl R, Beogo I, Fobelets M, Deletroz C, Van Landuyt P, Dequanter $\mathrm{S}$, et al. e-Health interventions for healthy aging: a systematic review. Systematic Reviews. 2020; 9: 128.

[26] Recio-Rodríguez JI, Lugones-Sanchez C, Agudo-Conde C, González-Sánchez J, Tamayo-Morales O, Gonzalez-Sanchez S, et al. Combined use of smartphone and smartband technology in the improvement of lifestyles in the adult population over 65 years: study protocol for a randomized clinical trial (EVIDENT-Age study) BMC Geriatrics. 2019; 19: 19.

[27] Kato S, Ando M, Kondo T, Yoshida Y, Honda H, Maruyama S. Lifestyle intervention using the Internet of Things (IoT) for the elderly: a study protocol for a randomized control trial (the BESTLIFE study). Nagoya Journal of Medical Science. 2018; 80: 175182.

[28] Cattivelli R, Castelnuovo G, Musetti A, Varallo G, Spatola CAM,
Riboni FV, et al. ACTonHEALTH study protocol: promoting psychological flexibility with activity tracker and $\mathrm{mHealth}$ tools to foster healthful lifestyle for obesity and other chronic health conditions. Trials. 2018; 19: 659.

[29] Abusaada H, Elshater A. COVID-19 challenge, information technologies, and smart cities: considerations for well-being. International Journal of Community well-being. 2020; 3: 417-424.

[30] Madhav KC, Sherchand SP, Sherchan S. Association between screen time and depression among US adults. Preventive Medicine Reports. 2017; 8: 67-71.

[31] Boers E, Afzali MH, Newton N, Conrod P. Association of screen time and depression in adolescence. JAMA Pediatrics. 2019; 173: 853.

[32] Goyal K, Chauhan P, Chhikara K, Gupta P, Singh MP. Fear of COVID 2019: first suicidal case in India! Asian Journal of Psychiatry. 2020; 49: 101989.

[33] Paul J, Jefferson F. A comparative analysis of student performance in an online vs. face-to-face environmental science course from 2009 to 2016. Frontiers in Computer Science. 2019; 1: 7. 